\title{
Milk and dairy products as a possible source of environmental transmission of Helicobacter pylori
}

\author{
Zora Št’ástková, Pavlína Navrátilová, Aneta Gřondělová \\ University of Veterinary and Pharmaceutical Sciences Brno, \\ Department of Animal Origin Food \& Gastronomic Sciences, Brno, Czech Republic
}

Received February 4, 2021

Accepted August 31, 2021

\begin{abstract}
Helicobacter pylori $(H$. pylori) is found worldwide, and it is estimated that more than $50 \%$ of the population is infected. The presence of $H$. pylori in the gastrointestinal tract is associated with the occurrence of serious human diseases such as chronic gastritis, duodenal ulcer or gastric cancer. Therefore, the International Agency for Research on Cancer classified H. pylori as a Group 1 carcinogen in 1994. The routes of $H$. pylori transmission are not yet precisely known. Many authors agree that humans may become infected by H. pylori through foodstuffs. Milk is one of the basic foods of people of all age categories. Helicobacter pylori has been isolated from milk derived from various livestock, such as cows, sheep, goat, camel or buffalo milk. This review research paper indicates that $H$. pylori may be present in different types of foods and suggests that consumption of milk and selected dairy products may be a source of $H$. pylori infection for humans.
\end{abstract}

Epidemiology, foodstuff, pathogen

In 1982, Australian pathologists Robin Warren and Barry Marshall first isolated H. pylori bacterium from gastric tissue. However, this bacterium was originally named Campylobacter pyloridis, which was later corrected to Campylobacter pylori, on the basis of similar properties with representatives of Campylobacter spp., such as the habitat and the culture medium for isolation. However, more detailed studies indicated that C. pylori should be included in a new genus. The term Helicobacter pylori, used since 1985, means a spiral rod in the lower part of the stomach (Gomes and De Martinis 2004).

It is a gram-negative, microaerophilic motile bacterium colonising the gastric mucosa. The presence of $H$. pylori in the gastrointestinal tract is associated with the occurrence of serious human diseases such as chronic gastritis, duodenal ulcer or gastric cancer. Therefore, the International Agency for Research on Cancer, established within the World Health Organization, classified H. pylori as a Group 1 carcinogen in 1994 (Guessoum et al. 2018).

\section{Epidemiology}

Helicobacter pylori bacterium is found worldwide, and it is estimated that more than $50 \%$ of the population is infected (Kao et al. 2016). Humans can become infected with this bacterium all throughout their lives (Quaglia and Dambrosio 2018). Helicobacter pylori has been reported to cause gastritis, peptic ulcer, adenocarcinoma, and MALT (mucosaassociated lymphoid tissue) lymphoma. According to the available data, 20 to $90 \%$ of hospitalised patients with gastrointestinal disorders were infected with $H$. pylori strains (Talimkhani and Mashak 2017). The prevalence of $H$. pylori infection depends to a large extent on age, geographical area or the socio-economic status (Brown 2000).

Address for correspondence:

MVDr. Zora Št'ástková, Ph.D.

University of Veterinary and Pharmaceutical Sciences Brno

Department of Animal Origin Food \& Gastronomic Sciences

Palackého tř. 1946/1, 61242 Brno

Czech Republic

Phone: +420541562 721

E-mail: stastkovaz@vfu.cz

http://actavet.vfu.cz 
The socio-economic status includes a number of factors. The increased incidence of infection in the population is mainly due to high population density, low levels of hygiene or a lack of sanitation. Studies have shown that contracting the H. pylori infection is closely associated with a low socioeconomic status (Mitchell and Katelaris 2016).

There has been a significant difference in the prevalence of the $H$. pylori infection between developing and developed countries (Perez-Perez et al. 2004). Helicobacter pylori was detected in more than $80 \%$ of the population in developing countries (Quaglia and Dambrosio 2018). In these countries, people are more often exposed to sources of infection than people from developed countries (Vale and Vítor 2010). In developed countries, the prevalence of infection is lower, below $40 \%$. While in developing countries, young people are also affected by the infection, in developed countries, the incidence is significantly lower in children than in adults (Quaglia and Dambrosio 2018). According to the available studies, the infection prevalence in the world has been decreasing due to improved sanitary conditions (Zamani et al. 2017).

The assessment of pathogenic virulence genes and genotypes is important for the epidemiology of $H$. pylori. VacA (vacuolating cytotoxin A) and $\operatorname{cag} A$ (cytotoxin associated gene A) are the most important markers of virulence detected in $H$. pylori strains. They are isolated in cases of gastrointestinal disorders but also from foodstuffs (Talimkhani and Mashak 2017). The gene encoding VacA belongs to a group of genes with a variable genotype or structure. It is associated with damage to gastric epithelial cells. This gene is found in virtually all $H$. pylori strains. It is polymorphic and includes variable signalling regions (type $s 1$ or type $s 2$ ), a mid-region (type $m 1$ or type $m 2$ ) and a recently identified intermediate-region (type i1, i2 and i3) (Palframan et al. 2012; Saeidi and Sheikhshahrokh 2016). Type $s 1$ is further divided into subtypes $s 1 a, s 1 b$, and $s 1 c$; and $m 1$ into subtypes $m l a$ and $m 1 b$ (Gilani et al. 2017). The mosaic combination of allelic types with $s$ and $m$ regions determines a specific cytotoxin and subsequently the pathogenicity of the bacterium (Hemmatinezhad et al. 2016). For example, the combination of $s 1 / \mathrm{m} 1$ alleles is associated with an increased risk of gastric cancer (Kao et al. 2016). CagA has been associated with ulceration, inflammation, and gastric cancer (Talimkhani and Mashak 2017).

Urease is another important virulence factor, in addition to the already mentioned VacA and $\operatorname{cag} A$. Urease is an enzyme hydrolysing urea to carbon dioxide and ammonia, thus ensuring the survival of $H$. pylori in an acidic environment (Velázquez and Feirtag 1999). However, ammonia production damages the gastric epithelium and carcinogenic substances are formed in association with neutrophil metabolites, which may be involved in tumour development in this area (Roesler et al. 2014).

Flagella are an essential factor of virulence involved in the $H$. pylori colonisation process. The composition of the flagella is as follows: a membrane, filaments, lipopolysaccharides and proteins (Sukri et al. 2020). The $f l a A$ and $f l a B$ genes encode flagellin proteins, essential for perfect motility and persistent gastric mucosal infection (Cellini and Donelli 2000).

Helicobacter pylori virulence factors may also include adhesins located on the surface of a bacterial cell, by which the bacterium adheres to receptors in the gastric epithelium. These include BabA (blood-antigen binding protein A), SabA (sialic acid-binding adhesin), as well as NAP (neutrophil-activating protein), Hsp60 (heat shock protein 60), AlpA and AlpB (adherence-associated proteins), HopZ (outer membrane protein), and LabA (lacdiNAc-binding adhesin) (Kao et al. 2016).

\section{Microbiological characteristics}

Helicobacter pylori is a spiral-shaped Gram negative bacterium which measures 2 to $4 \mu \mathrm{m}$ in length and ranges in width from 0.5 to $1 \mu \mathrm{m}$ (Kusters et al. 2006). The bacterium may occur in three forms (Andersen and Rasmussen 2009): 
- A viable spiral form which is culturable (infectious);

- A viable cocoid form, non-culturable (inability to grow on agar plates);

- A non-viable degenerative and non-culturable form.

The change in the H. pylori shape from a rod to a cocoid form occurs under adverse environmental conditions, such as insufficient nutrient supply (Andersen and Rasmussen 2009).

The bacteria require a microaerophilic environment. For optimal growth, the oxygen level should be 2 to $5 \%$ and the carbon dioxide level from 5 to $10 \%$. The atmosphere should also have high air humidity (98\%). The standard composition of the atmosphere for the growth of $\mathrm{H}$. pylori used in laboratories is $5 \% \mathrm{O}_{2}+10 \% \mathrm{CO}_{2}+85 \% \mathrm{~N}_{2}$ (Kusters et al. 2006). As specified by Jiang and Doyle (1998), the bacterium is able to grow even at $\mathrm{pH} 4.5$. However, they recorded optimal growth at $\mathrm{pH}$ from 5.5 to 7.3 . In their study, H. pylori also did not grow in an environment with $2 \% \mathrm{NaCl}$. However, in an environment of 0.5 to $1 \% \mathrm{NaCl}$, it grew relatively well. The growth of $H$. pylori also requires water activity in the range of 0.96 to 0.98 , suggesting that the bacterium is unable to grow in many types of foodstuffs (Jiang and Doyle 1998).

The motility of the bacterium is ensured by four to six unipolar sheathed flagella with a spherical extension at the end. This part is an extension of the flagellar sheath. Each flagellum is approximately $30 \mu \mathrm{m}$ long (Dunn et al. 1997). Helicobacter pylori grows from 30 to $37{ }^{\circ} \mathrm{C}$, with the optimal growth at $37{ }^{\circ} \mathrm{C}$. Growth at $42{ }^{\circ} \mathrm{C}$ is variable, while the bacterium is unable to grow at $25^{\circ} \mathrm{C}$ (Velázquez and Feirtag 1999). In the case of culturing $H$. pylori, it is necessary to enrich the substrate with certain supplements, such as sheep or horse blood, haemoglobin, yolk emulsion, etc. (Quaglia and Dambrosio 2018). Helicobacter pylori shows a positive catalase and oxidase reaction, as well as strong urease positive activity. Bacteria show a negative reaction to hippurate (Velázquez and Feirtag 1999).

\section{Transmission pathways of $\boldsymbol{H}$. pylori}

The routes of $H$. pylori transmission are not yet precisely known (Vale and Vítor 2010). The infectious dose of $H$. pylori is low and therefore even a small number of $H$. pylori cells may pose a potential health risk to humans (Quaglia et al. 2020). There has been a study aimed at determining the minimum infectious dose in humans, which has found that the minimum infectious dose is close to the value of $10^{5}$ of colony forming units (CFU) (Graham et al. 2004). The available scientific data indicate that the spread of $H$. pylori has two possible alternatives, namely the transmission from human to human and through the environment (water, milk, etc.) to human (Zamani et al. 2017).

Person to person transmission may take place through the oral-oral route, the faecal-oral route, and the gastro-oral route. However, there are no data to determine the predominance of either of the transmission pathways (Quaglia et al. 2020). The gastro-oral transmission route may take place through gastric juices, gastroesophageal reflux, or gastric regurgitation (Brown 2000; Vale and Vítor 2010). This has been confirmed by a study conducted by Parsonnet et al. (1999), when H. pylori was present in large amounts in vomit. The vomiting process may spread the bacteria into the air. However, the aerosol is an unlikely source of infection due to the short duration of contamination. Helicobacter pylori DNA has also been detected in human faeces (Brown 2000). In the case of oral-oral transmission, studies confirm that saliva can serve as a $H$. pylori transmission vector. Some scientists have been successful in isolating H. pylori from dental plaque (Brown 2000).

Helicobacter pylori primarily colonizes the antral part of the human stomach. Some bacteria adhere to the gastric mucosa and some remain in the lumen of the stomach as nonadhering bacteria. These microorganisms can then continue freely into the intestine and, 
together with the faeces, enter the environment. In the case of dyspepsia (e.g. vomiting), non-adherent bacteria may enter the oral cavity. Numerous studies have confirmed the presence of $H$. pylori DNA in the previously mentioned saliva and dental plaque (Andersen and Rasmussen 2009).

Animals, foodstuff, and their importance in the H. pylori transmission

Many authors agree that humans may become infected by $H$. pylori through foodstuffs (Fujimura et al. 2002; Angelidis et al. 2011; Mousavi et al. 2014). Some scientists refer to this bacterium as a pathogen causing foodborne illness. This is due to some microbiological and epidemiological properties of this microorganism. For example, there is a high prevalence of infection in the family or among individuals living in institutions (Quaglia et al. 2007).

The foodstuffs which could theoretically provide conditions suitable for the survival of H. pylori are those whose water activity is higher than 0.97 and the $\mathrm{pH}$ is in the range of 4.9-6.0. Therefore, the bacterium is likely to grow in most foods. Examples of foods in which $H$. pylori has been detected are provided in Table 1 . The bacterium is characterised by its ability to survive for a long time in an environment with high humidity and low acidity, especially when stored in the cold (Gomes and De Martinis 2004). It is this capacity of $H$. pylori to survive in food that supports the theory that primary food contamination (animal reservoir) or secondary contamination as a result of improper handling (human reservoir) may serve as a means of $H$. pylori transmission (Vale and Vítor 2010).

Table 1. Detection of the occurrence of H. pylori in selected foodstuffs (adapted from Quaglia and Dambrosio 2018).

\begin{tabular}{llcr}
\hline Foodstuff type & Method & Number of samples & $\begin{array}{c}\text { Percentage of } \\
\text { positive samples (\%) }\end{array}$ \\
\hline Raw sheep milk & Culture & 63 & 2.60 \\
& PCR & & 63.00 \\
Raw cow's milk & Nested-PCR & 110 & 50.00 \\
Raw goat milk & Nested-PCR & 160 & 25.60 \\
Raw buffalo milk & PCR & 80 & 15.00 \\
Raw camel milk & PCR & 60 & 13.30 \\
Cheese (traditional Iranian) & PCR & 100 & 30.00 \\
Butter (traditional Iranian) & PCR & 100 & 5.00 \\
Cream (traditional Iranian) & PCR & 100 & 15.00 \\
Ice cream (traditional Iranian) & PCR & 100 & 27.00 \\
Raw meat & PCR & 400 & 26.25 \\
Hamburger & Nested-PCR & 80 & 1.42 \\
Lettuce & PCR & 80 & 13.75 \\
Spinach & PCR & 80 & 6.25 \\
\hline
\end{tabular}

Helicobacter pylori has been detected in drinking and sea water, as well as in foods of animal origin, and therefore animals are believed to serve as a reservoir for the microorganism (Quaglia et al. 2008). This has been confirmed by several studies which have found that there is a high prevalence of antibodies to $H$. pylori in slaughterhouse workers, veterinarians or butchers (Tabatabaei 2012). Even domestic animals can be a source of $H$. pylori. This bacterium was detected in dogs and more rarely in cats (Neiger and Simpson 2000; Erginsoy at al. 2006). Furthermore, H. pylori has also been detected in raw vegetables. Several studies have been conducted showing that vegetable contamination may occur through irrigation water (Zamani et al. 2017). According to 
studies, H. pylori DNA has been detected inside Candida yeasts, which can serve as a reservoir or method for protecting the bacterium in the natural environment. These yeasts are often found in water, in food, but also in the human gastrointestinal or urinary tract (Vale and Vítor 2010; Zamani et al. 2017).

\section{Milk and dairy products}

Milk is one of the basic foods of people of all age categories. It is usually processed into dairy products such as butter, yogurt, cream or cheese. Millions of people around the world consume milk and dairy products on a daily basis, and therefore the hygienic quality of milk is very important (Mousavi et al. 2014).

Milk contamination usually occurs during milking. Helicobacter pylori enters the surface of the mammary gland (udder) from various sources, contaminated with the faeces of infected animals. The source may include soil, manure, bedding, or water. Poor hygiene practices on farms contribute to the spread of bacteria from animal to animal during milking, through contaminated milking equipment or the hands of milkers or the wipes used (Osman et al. 2015). Milk contaminated during collection is deemed to be one of the most likely carriers of infection (Quaglia et al. 2007).

Helicobacter pylori has been isolated from milk derived from various livestock, such as cow's, sheep, goat, camel or buffalo milk (Zamani et al. 2017). The frequency of H. pylori occurrence in the milk of various livestock is provided in Table 2.

Table 2. Frequency of occurrence of $H$. pylori in milk originating from various livestock (Verraes et al. 2014).

\begin{tabular}{ll}
\hline Raw milk type & Occurrence frequency (\%) \\
\hline Cow's milk & From 14.1 to 50.0 \\
Goat milk & From 8.7 to 25.6 \\
Sheep milk & 0 to 60.3 \\
Buffalo milk & 2.45 \\
Camel milk & 6.0 \\
\hline
\end{tabular}

Based on this fact, livestock may be a potential source of $H$. pylori and a potential riskboth forpeople handling these animals and for consumers of their products (Guessoum et al. 2018). The ability of $H$. pylori to survive in an acidic environment is dependent on urea. It is present in milk and may be responsible for the long-term survival of the bacterium in this food (Jiang and Doyle 1998).

According to a study conducted by Fujimura et al. (2002) in Japan, semi-nested PCR was used to detect $H$. pylori DNA in $72 \%$ of raw cow's milk samples. In Greece, Angelidis et al. (2011) detected H. pylori in 20\% of raw cow's milk samples. Quaglia et al. (2008) found H. pylori in raw sheep, cow's and goat milk originating in northern Italy. The prevalence of this bacterium was $33.0 \%, 50.0 \%$, and $25.6 \%$. The team of authors Ranjbar et al. (2018) studied traditional dairy products originating in Iran. Specifically, they tested cheese, cream, butter and yogurt for the presence of $H$. pylori. They showed that $11.53 \%$ of the cheese samples, $5.00 \%$ of the cream samples, $4.00 \%$ of the butter samples and $1.11 \%$ of the yoghurt samples were positive for $H$. pylori. The detection of this pathogen in dairy products made in Iran has also been addressed by Mousavi et al. (2014). In their work, they examined dairy products made from raw milk, namely cheese, cream, butter and ice cream. Helicobacter pylori was detected in $30 \%$ of cheese samples, $15 \%$ of cream samples, $5 \%$ of butter samples, and $27 \%$ of ice cream samples. The high incidence of $H$. pylori in traditional Iranian cheeses may be due in particular to the low temperature used to treat raw milk, around $40{ }^{\circ} \mathrm{C}$. In yogurt, unlike milk, H. pylori is unable to survive. The growth of $H$. pylori is affected by the acidic $\mathrm{pH}$ and organic acids produced by the growth of lactic acid bacteria (Quaglia and Dambrosio 2018).

In some studies, researchers failed to isolate $H$. pylori from milk. The team of authors Jiang and Doyle (2002) were unable to detect $H$. pylori in raw cow's milk using the PCR method. Helicobacter pylori was not isolated from raw sheep milk originating in Turkey using the culture method applied by Turutoglu and Mudul (2002). Tabatabaei (2012) 
failed to detect the presence of Helicobacter spp. in a single milk sample using a culture method from 20 raw cow's milk samples from south-western Iran. This could be due to the presence of H. pylori in a cocoid, viable but non-culturable form (VNC, viable nonculturable form). This is because this form cannot be detected using the culture method. As reported by Bianchini et al. (2015), the impossibility to isolate $H$. pylori using the culture method may be due to an overgrowth of contaminating microflora, making it impossible to identify small $H$. pylori colonies after the culturing. Another issue may consist in the selective media for culturing $H$. pylori which have been primarily developed for culturing microorganisms from clinical samples whose microflora is different from the food microflora. The impossibility to isolate $H$. pylori from samples may be due to the geographical distribution of the bacterium (Jiang and Doyle 2002).

Several studies have been conducted addressing the survival of $H$. pylori in milk and dairy products. According to the study carried out by Fan et al. (1998), H. pylori was found to be able to survive in artificially contaminated pasteurised milk for the period of 10 days at a storage temperature of $4{ }^{\circ} \mathrm{C}$. According to the research conducted by Quaglia et al. (2007), H. pylori was able to survive in artificially contaminated UHT milk for a period of 12 days, and in pasteurized milk for a period of 9 days at a storage temperature of $4{ }^{\circ} \mathrm{C}$.

\section{Probiotics and $\boldsymbol{H}$. pylori}

Today, antibiotics (amoxicillin, clarythromycin, metronidazole, etc.) are used in combination with antisecretory therapy to treat infections caused by H. pylori. However, there is a problem consisting in the increasing antimicrobial resistance of $H$. pylori to antibiotics. Therefore, research in this area focuses on new therapeutic solutions, such as the use of probiotics in the treatment of H. pylori infection (Švestka 2011).

Probiotics are defined as living, non-pathogenic organisms added to feed or food and intended to have a positive effect on the consumer by improving the balance of their intestinal microflora (Cazzato et al. 2004). In clinical practice, the most commonly used probiotics include Lactobacillus spp., Bifidobacterium spp., Bacillus spp., Escherichia coli, Streptococcus thermophilus, and Sacharomyces boulardii (Franceschi et al. 2007).

\section{Effect of probiotics on $H$. pylori}

Studies indicate that probiotics have various effects. First, there may be in direct competition with $H$. pylori, causing the inhibition of adherence and the production of metabolites and antimicrobial molecules. Second, probiotics reduce the incidence of side effects associated with antibiotics administration (Cazzato et al. 2004).

In a healthy person, lactobacilli are the dominant bacteria in the stomach. Their concentration here ranges from 0 to $10^{3} \mathrm{CFU} / \mathrm{ml}$ of liquid. The abilities of lactobacilli of human origin are assumed to include the colonisation of the epithelial mucosa surface. They may thus interfere with pathogens in vivo (Cazzato et al. 2004). Owing to the various components of the bacterial surface, $H$. pylori may tightly adhere to epithelial cells. A study was conducted in which two of the nine Lactobacillus reuteri (L. reuteri) strains were able to bind to glycolipid receptors (asialo-GMI and sulphatide) and thus inhibit the binding of $H$. pylori to these receptors. With the help of these strains of L. reuteri, $H$. pylori infection could be prevented in the initial stage of colonisation of the gastric mucosa (Felley and Michetti 2003). Some lactobacilli have the capacity to synthesize antimicrobial compounds belonging to bacteriocins. Other substances secreted by these bacteria include lactic acid, acetic acid and hydrogen peroxide. Some authors consider the relatively large amount of lactate produced by lactobacilli to be an inhibitory factor in $H$. pylori. Lactic acid, which has an antimicrobial effect by lowering the $\mathrm{pH}$, can inhibit H. pylori urease (Lesbros-Pantoflickova et al. 2007). The strains capable of inhibiting 
or killing H. pylori include L. acidophilus, L. casei, L. johnsonii La1, and L. salivarius (Hamilton-Miller 2003). However, there are specific probiotic strains which show antibacterial activity due to the production of antibiotic compounds. An example may include the supernatant of Bacillus subtilis. The inhibition of $H$. pylori growth is thus independent of organic acid concentration or $\mathrm{pH}$ (Cazzato et al. 2004).

There may be side effects (e.g. bloating, nausea, diarrhoea, constipation, vomiting, loss of appetite, or epigastric pain) occurring when taking antibiotics (to treat the $H$. pylori infection) at high doses. The side effects may reduce the effectiveness of the therapy and affect the patient's treatment cooperation. Interrupting the therapy due to the occurrence of side effects may increase the risk of developing antibiotic-resistant strains. Therefore, new strategies have been developed to improve the tolerability of $H$. pylori eradication therapies, including the use of probiotics, among other things. This has been confirmed by a study in previously asymptomatic patients infected with $H$. pylori, undergoing standard triple eradication therapy and receiving Bacillus clausii supplementation for two weeks. The decreased occurrence of nausea, diarrhoea and epigastric pain has been reported in these patients. Similar results were obtained when using $S$. boulardii and $L$. casei. In another study, randomly selected patients (infected by H. pylori) were divided into two groups, one taking probiotics (Lactobacillus GG or S. boulardii or a combination of Lactobacillus spp. and bifidobacteria), while the other receiving placebo during the therapy and seven days after that. A significantly lower incidence of diarrhoea and taste disturbances was observed in patients taking probiotics (Cazzato et al. 2004; Franceschi et al. 2007).

\section{Conclusion}

Helicobacter pylori is a bacterium widely spread in the human population. However, the routes of transmission to humans have not been elucidated. It has been found that this bacterium is present in many types of food (vegetables, meat, milk, dairy products, etc.). This review focuses on the occurrence of $H$. pylori in milk and dairy products, which are among the basic foods. The studies indicate that $H$. pylori may be present in these foods, suggesting that consumption of milk and selected dairy products may be a source of $H$. pylori infection for humans. In order to confirm the unambiguous transmission of bacteria by food or water to humans, more research is needed into other foodstuffs of animal origin.

\section{Acknowledgements}

The work was financially supported by the Internal Grant Agency of the University of Veterinary and Pharmaceutical Sciences Brno (grant no. 224/2020/FVHE).

\section{References}

Andersen LP, Rasmussen L 2009: Helicobacter pylori-coccoid forms and biofilm formation. FEMS Immunol Med Microbiol 56: 112-115

Angelidis AS, Tirodimos I, Bobos M, Kalamaki MS, Papageorgiou DK, Arvanitidou M 2011: Detection of Helicobacter pylori in raw bovine milk by fluorescence in situ hybridization (FISH). Int J Food Microbiol 151: $252-256$

Bianchini V, Recordati C, Borella L, Gualdi V, Scanziani E, Selvatico E, Luini M 2015: Helicobacteraceae in bulk tank milk of dairy herds from Northern Italy. BioMed Res Int 2015: 1-4

Brown LM 2000: Helicobacter pylori: Epidemiology and routes of transmission. Epidemiol Rev 22: 283-297

Cazzato IA, Candelli M, Nista EC, Gasbarrini G, Gasbarrini A 2004: Role of probiotics in Helicobacter pylori infections. J Food Nutr Res 48: 26-31

Cellini L, Donelli G 2000: Virulence Factors of Helicobacter pylori. Microb Ecol Health Dis 2: 259-262

Dunn BE, Cohen H, Blaser MJ 1997: Helicobacter pylori. Clin Microbiol Rev 10: 720-741

Erginsoy SD, Sözmenö M, Özcan K 2006: Gastric Helicobacter-like organisms in stray cats. Acta Vet Brno 75: 91-98 
Fan X-G, Chua A, LI T-G, Zeng Q-S 1998: Survival of Helicobacter pylori in milk and tap water. J Gastroenterol Hepatol 13: 1096-1098

Felley C, Michetti P 2003: Probiotics and Helicobacter pylori. Best Pract Res Clin Gastroenterol 17: 785-791

Franceschi F, Cazzato A, Nista EC, Scarpellini E, Roccarina D, Gigante G, Gasbarrini G, Gasbarrini A 2007: Role of probiotics in patients with Helicobacter pylori infection. Helicobacter 12: 59-63

Fujimura S, Kawamura T, Kato T, Tateno H, Watanabe A 2002: Detection of Helicobacter pylori in cow's milk. Lett App Microbiol 35: 504-507

Gilani A, Razavilar V, Rokni N, Rahimi E 2017: VacA and cagA genotypes status and antimicrobial resistence properties of Helicobacter pylori strains isolated from meat products in Isfahan province, Iran. Iran J Vet Res 18: $97-102$

Gomes BC, De Martinis ECP 2004: The significance of Helicobacter pylori in water, food and environmental samples. Food Control 15: 397-403

Graham DY, Opekun AR, Osato MS, El-Zimaity HMT, Lee CK, Yamaoka Y, Qureshi WA, Cadoz M, Monath TP 2004: Challenge model for Helicobacter pylori infection in human volunteers. Gut 53: 1235-1243

Guessoum M, Guechi Z, Adnane M 2018: First-time serological and molecular detection of Helicobacter pylori in milk from Algerian local-breed cows. Vet World 11: 1326-1330

Hamilton-Miller JMT 2003: The role of probiotics in the treatment and prevention of Helicobacter pylori infection. Int J Antimicrob Agents 22: 360-366

Hemmatinezhad B, Momtaz H, Rahimi E 2016: VacA, cagA, iceA and oipA genotypes status and antimicrobial resistance properties of Helicobacter pylori isolated from various types of ready to eat foods. Ann Clin Microbiol Antimicrob 15: 1-9

Jiang X, Doyle MP 1998: Effect of environmental and substrate factors on survival and growth of Helicobacter pylori. J Food Prot 61: 929-933

Jiang X, Doyle MP 2002: Optimizing enrichment culture conditions for detecting Helicobacter pylori in foods. J Food Prot 65: 1949-1954

Kao CH-Y, Sheu B-S, Wu J-J 2016: Helicobacter pylori infection: An overview of bacterial virulence factors and pathogenesis. Biomed J 39: 14-23

Kusters JG, Van Vliet AHM, Kuipers ME 2006: Pathogenesis of Helicobacter pylori infection. Clin Microbiol Rev 19: 449-490

Lesbros-Pantoflickova D, Corthésy-Theulaz I, Blum AL 2007: Helicobacter pylori and probiotics. J Nutr 137: $812-818$

Mitchell H, Katelaris P 2016: Epidemiology, clinical impacts and current clinical management of Helicobacter pylori infection. Med J Aust 204: 376-380

Mousavi S, Dehkordi FS, Rahimi E 2014: Virulence factors and antibiotic resistance of Helicobacter pylori isolated from raw milk and unpasteurized dairy products in Iran. J Venom Anim Toxins incl Trop Dis 20: 1-7

Neiger R, Simpson KW 2000: Helicobacter infection in dogs and cats: facts and fiction. J Vet Intern Med 14: $125-133$

Osman EY, El-Eragi AMS, Musa AM, El-Magboul SB, A/Rahman MB, Abdo AE 2015: Detection of Helicobacter pylori glm $M$ gene in bovine milk using nested polymerase chain reaction. Vet World 8: 913-917

Palframan SL, Kwok T, Gabriel K 2012: Vacuolating cytotoxin A (VacA), a key toxin for Helicobacter pylori pathogenesis. Front Cell Infect Microbiol 2: 1-9

Parsonett J, Shmuely H, Haggerty T 1999: Fecal and oral shedding of Helicobacter pylori from healthy infected adults. J Am Med Assoc 282: 2240-2245

Perez-Perez GI, Rothenbacher D, Brenner H 2004: Epidemiology of Helicobacter pylori infection. Helicobacter 9: 1-6

Quaglia NC, Dambrosio A 2018: Helicobacter pylori: A foodborne pathogen? World J Gastroenterol 24: 3472-3487

Quaglia NC, Dambrosio A, Normanno G, Parisi A, Firinu A, Lorusso V, Celano GV 2007: Survival of Helicobacter pylori in artificially contaminated ultrahigh temperature and pasteurized milk. Food Microbiol 24: 296-300

Quaglia NC, Dambrosio A, Normanno G, Parisi A, Patrono R, Ranieri G, Rella A, Celano GV 2008: High occurrence of Helicobacter pylori in raw goat, sheep and cow milk inferred by glmM gene: A risk of foodborne infection? Int J Food Microbiol 124: 43-47

Quaglia NC, Storelli MM, Scardocchia T, Lattanzi A, Celano GV, Monno R, Dambrosio A 2020: Helicobacter pylori: Survival in cultivable and non-cultivable form in artificially contaminated Mytilus galloprovincialis. Int J Food Microbiol 312: 1-6

Ranjbar R, Yadollahi Farsani F, Safarpoor Dehkordi F 2019: Antimicrobial resistance and genotyping of vacA, $\operatorname{cag} A$, and ice A alleles of the Helicobacter pylori strains isolated from traditional dairy products. J Food Saf 39: 1-9

Roesler BM, Rabelo-Goncalves EMA, Zeitune, JMR 2014: Virulence factors of Helicobacter pylori: A Review. Clin Med Insights: Gastroenterol 7: 9-17

Saeidi E, Sheikhshahrokh A 2016: VacA genotype status of Helicobacter pylori isolated from foods with animal origin. BioMed Res Int 2016: 1-6

Sukri A, Hanafiah A, Zin NM, Kosai, NR 2020: Epidemiology and role of Helicobacter pylori virulence factors in gastric cancer carcinogenesis. APMIS 128: 150-161 
Švestka T 2011: Infekce Helicobacter pylori. (in Czech, Helicobacter pylori infection) Medicína pro praxi 8: 123-126

Tabatabaei M 2012: Application of molecular and cultural methods for identification of Helicobacter spp. in different animal sources. Glob Vet 8: 292-297

Talimkhani A, Mashak Z 2017: Prevalence and genotyping of Helicobacter pylori isolated from meat, milk and vegetable in Iran. Jundishapur J Microbiol 10: 1-6

Turutoglu H, Mudul S 2002: Investigation of Helicobacter pylori in raw sheep milk samples. J Vet Med 49: 308-309

Vale FF, Vítor JMB 2010: Transmission pathway of Helicobacter pylori: Does food play a role in rural and urban areas? Int J Food Microbiol 138: 1-12

Velázquez M, Feirtag JM 1999: Helicobacter pylori: characteristics, pathogenicity, detection methods and mode of transmission implicating foods and water. Int J Food Microbiol 53: 95-104

Verraes C, Claeys W, Cardoen S, Daube G, De Zutter L, Imberechts H, Dierick K, Herman L 2014: A review of the microbiological hazards of raw milk from animal species other than cows. Int Dairy J 39: 121-130

Zamani M, Vahedi A, Maghdouri Z, Shokri-Shirvani J 2017: Role of food in environmental transmission of Helicobacter pylori. Caspian J Intern Med 8: 146-152 